\title{
Wellens' syndrome with segmental wall-motion abnormalities
}

This article was published in the following Dove Press journal:

Open Access Emergency Medicine

I December 2010

Number of times this article has been viewed

\author{
Turgay Celik' \\ Baris Bugan' \\ Serdar Firtina' \\ Murat Celik ${ }^{2}$ \\ Sait Demirkol' \\ Atila lyisoy' \\ 'Gulhane Military Medical Academy, \\ Department of Cardiology, Ankara, \\ Turkey; ${ }^{2}$ Van Army District Hospital, \\ Department of Cardiology, \\ Van, Turkey
}

\begin{abstract}
Wellens' syndrome is a pattern of electrocardiographic T-wave changes associated with critical, proximal left anterior descending (LAD) artery stenosis. We herein report 2 cases of Wellens' syndrome with segmental wall-motion abnormalities The first case is a 50-year-old man admitted to the emergency department with typical chest pain. Admission ECG showed biphasic $\mathrm{T}$ waves in leads $\mathrm{V}_{1}-\mathrm{V}_{3}$ with inverted $\mathrm{T}$ waves in leads $\mathrm{V}_{4}-\mathrm{V}_{6}$, and cardiac enzymes were in normal limits. The second case is a 62-year-old woman admitted to the emergency department with chest pain on rest. Admission ECG showed deeply inverted T waves in leads $\mathrm{V}_{1}-\mathrm{V}_{4}$, and troponin $\mathrm{T}$ was minimally elevated. The critical lesions in the proximal segment LAD were successfully opened with stent deployments. Wall-motion abnormalities returned to normal after intervention.
\end{abstract}

Keywords: Wellens' syndrome, wall-motion abnormality, T-wave syndrome

\section{Introduction}

Wellens' syndrome was first described in 1982 by de Zwaan et al ${ }^{1}$. This condition is regarded as preinfarction state and consists of T-wave changes in ECG and critical narrowing of proximal left anterior descending coronary (LAD) artery with additional clinical and laboratory findings. Wellens' syndrome can be divided into 2 types according to the ECG pattern: cases with biphasic $\mathrm{T}$ waves are classified as type 1 and cases with deeply inverted $\mathrm{T}$ waves as type 2 . These changes are usually seen at leads $\mathrm{V}_{2}-\mathrm{V}_{3}$ and may involve leads $\mathrm{V}_{1}-\mathrm{V}_{4}$. Patients with Wellens' syndrome have an increased risk for anterior myocardial infarction and early invasive investigation is essential in the management of these cases. ${ }^{1-3}$ We herein report 2 cases of Wellens' syndrome with segmental wall-motion abnormalities and re-emphasize some critical points that should be kept in mind in the management of these patients.

\section{Case presentations Case I}

A 50-year-old man was admitted to the emergency department with typical chest pain on rest associated with intense diaphoresis. Admission ECG showed biphasic $\mathrm{T}$ waves in leads $\mathrm{V}_{1}-\mathrm{V}_{3}$ with inverted $\mathrm{T}$ waves in leads $\mathrm{V}_{4}-\mathrm{V}_{6}$ (Figure 1A). Physical examination was unremarkable and cardiac enzymes were within normal limits. He was quickly referred to the coronary care unit. On bedside echocardiographic examination, mild apical hypokinesis with a left ventricular ejection fraction of $55 \%$ was detected. Coronary angiography revealed a critical proximal LAD stenosis and then angioplasty with stent
Correspondence: Baris Bugan Staff of Cardiologist, Gulhane Military Medical Academy, Department of Cardiology, Etlik, Ankara, Turkey 06018 Tel +90 (3I2) 3044268 $\mathrm{Fax}+90(3 \mathrm{I}) 3044250$ Email bbugan@hotmail.com 


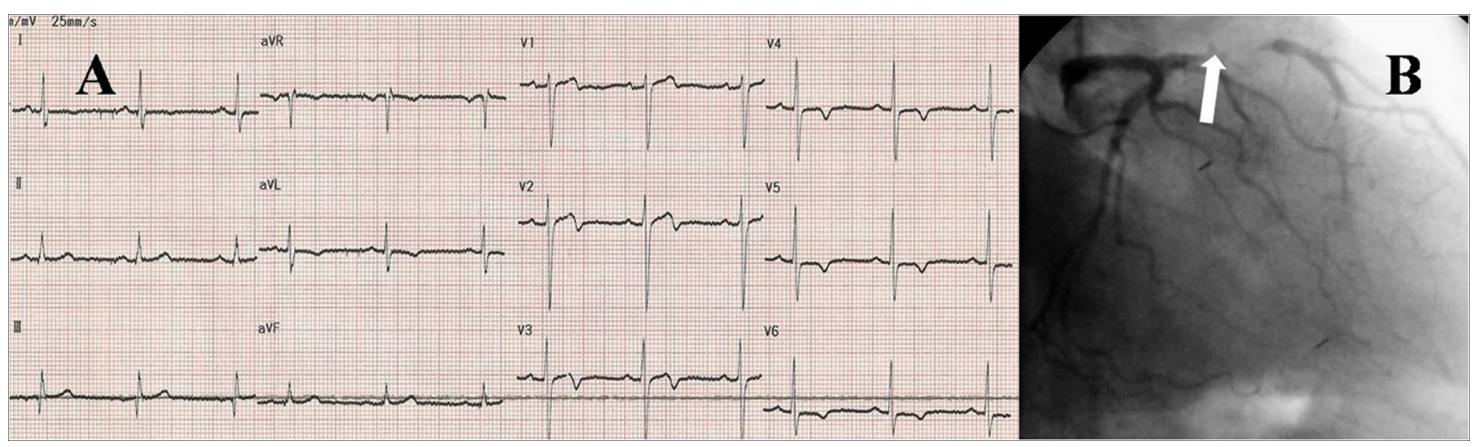

Figure I Electrocardiogram showing biphasic $T$ waves in leads $V_{1}-V_{3}$ with inverted $T$ waves in leads $V_{4}-V_{6}(A)$, and coronary angiogram revealing critical proximal left anterior descending artery lesion (B).

placement was performed successfully (Figure 1B). Wall-motion abnormality in apical segment returned to normal after intervention.

\section{Case 2}

A 62-year-old woman with a history of hypertension presented to the emergency department with chest pain on rest. Admission ECG showed deeply inverted $\mathrm{T}$ waves in leads $\mathrm{V}_{1}-\mathrm{V}_{4}$ (Figure 2A). Troponin $\mathrm{T}$ was found to be minimally elevated (peak troponin T value was $0.055 \mathrm{ng} / \mathrm{mL}$ ). Anterior and apical hypokinesis with an ejection fraction of $40 \%$ were detected on echocardiography. She was quickly referred to the coronary care unit for early invasive investigation. On coronary angiography, tight stenosis was observed in the proximal part of the LAD and then the lesion was successfully opened with stent deployment (Figure 2B). Wall-motion abnormality in anterior and apical segments returned to normal after intervention.

\section{Discussion}

The inverted $\mathrm{T}$ waves produced by myocardial ischemia are classically narrow and symmetrical; however, biphasic
T waves may also be associated with ischemia. In 1982, de Zwaan et al emphasized the importance of both types of T-wave changes, and first described the clinical and ECG criteria which is the predictor of extent myocardial infarction for a subgroup of acute coronary syndrome patients. ${ }^{1-3}$

In the original study, 145 patients admitted to hospital with unstable angina, and $26(18 \%)$ patients showed the typical ECG pattern. Twelve of 16 patients $(75 \%)$ who did not undergo coronary revascularization developed extensive anterior wall infarction within a few weeks of admission. ${ }^{1}$ In the second study of 1260 patients, 180 (14\%) patients demonstrated the ECG criteria, and angiographically significant LAD stenosis, varying from $50 \%$ to complete obstruction, was observed in all 180 patients. ${ }^{4}$

Two variants of precordial ST-T abnormalities have been described in Wellens' syndrome. The ST segment itself is often normal; if abnormal, it is minimally elevated, usually less than $1 \mathrm{~mm}$. The more common abnormality (75\%) is deeply inverted T waves in leads V2 and V3 (type 2). Biphasic T waves in leads V2 and V3 (type 1) is relatively rare $(25 \%)$. Although the ST segment and T-wave abnormalities are present in leads $\mathrm{V}_{2}$ and $\mathrm{V}_{3}$, it may also be seen in

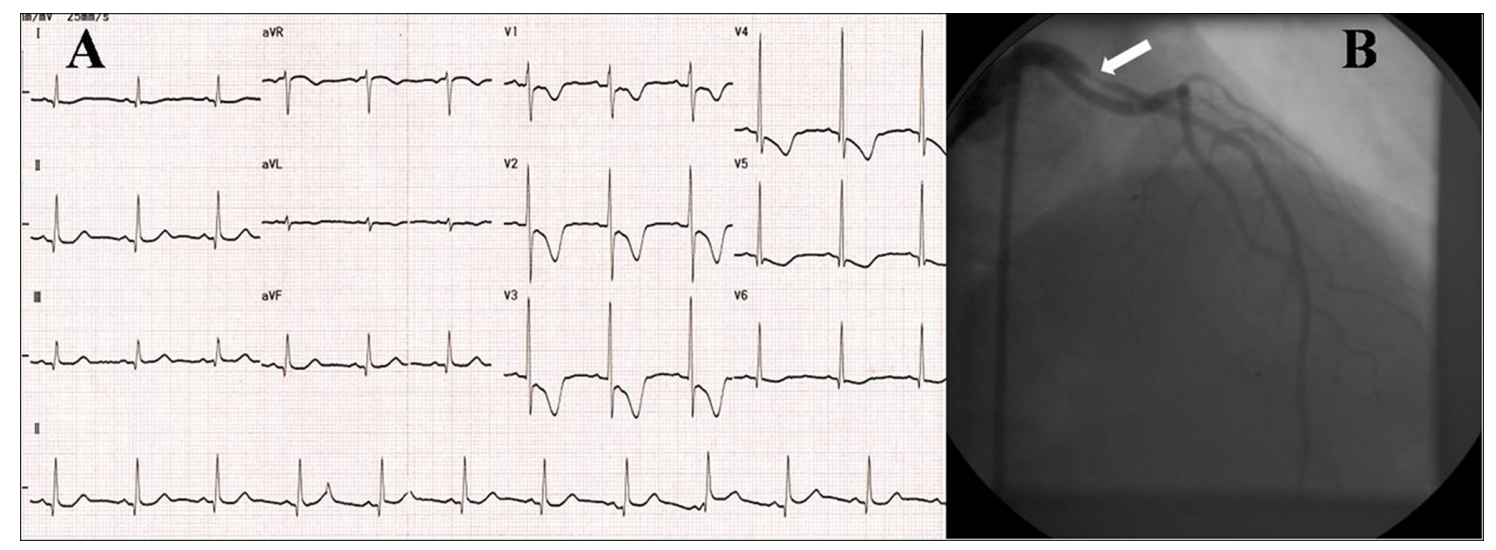

Figure 2 Electrocardiogram demonstrating deeply inverted $T$ waves in leads $V_{1}-V_{4}(\mathbf{A})$, and coronary angiogram showing $95 \%$ stenosis of proximal left anterior descending artery $(\mathbf{B})$. 
Table I Criteria for Wellens'syndrome

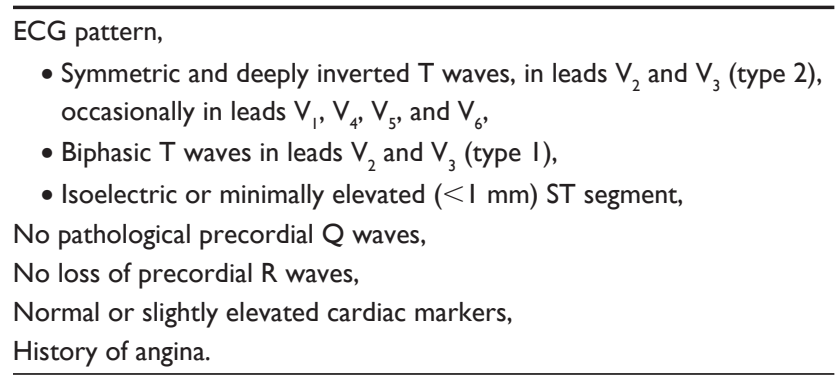

leads $\mathrm{V}_{1}-\mathrm{V}_{4}$ and occasionally in leads $\mathrm{V}_{5}-\mathrm{V}_{6}$. Approximately two-thirds of patients also had these changes in lead $V_{1}$ and three-quarters in lead $\mathrm{V}_{4}$. Patients with abnormalities in lead $\mathrm{V}_{4}$ occasionally had similar abnormalities in leads $\mathrm{V}_{5}$ or $\mathrm{V}_{6}$. The ECG abnormalities may develop during an angina-free period or during chest pain, and may normalize or develop into ST segment elevation. ${ }^{1-5}$ In the prospective study by de Zwaan et al, $60 \%$ of patients diagnosed with Wellens' syndrome had the characteristic ECG changes on admission and then $31 \%$ developed the changes within 24 hours, $5.6 \%$ within 2 days, $2.8 \%$ within 3 days, and $0.6 \%$ within 5 days. ${ }^{4}$

Differential diagnosis of $\mathrm{T}$ wave inversion comprises extensive clinical circumstances such as acute coronary syndrome, past myocardial infarction, acute pulmonary embolism, central nervous system injury, persistent juvenile $\mathrm{T}$ wave pattern, digitalis effect, left ventricular hypertrophy, bundle branch block, pre-excitation syndromes, acute myocarditis, and later stages of pericarditis; however the Wellens' syndrome may be easily diagnosed by considering the specific criteria in Table 1.,6

When the chest pain patient who presents with a powerful clinical description of acute coronary syndrome and ECG changes is detected, physicians should manage appropriate therapy and refer the patient to the coronary care unit. Provocative testing for certain diagnosis or risk stratification is risky in patients with Wellens' pattern and it may precipitate an acute myocardial infarction. ${ }^{2,3,5,6}$

Interestingly segmental wall-motion abnormalities were detected on echocardiography in our cases who had severe critical lesions on the proximal LAD. However wall-motion abnormalities improved after revascularization in all of these cases. Wall-motion abnormalities have not been extensively studied in Wellens' syndrome, and this issue needs further diagnostic criteria. ${ }^{3}$

\section{Conclusion}

Wellens' syndrome is a preinfarction stage of coronary artery disease, and it may be present with an angina-free period. Clinical and ECG criteria may provide exact diagnosis of this syndrome. Once Wellens' syndrome has been diagnosed, the patients should be referred to the coronary care unit for early invasive approach. In patients with Wellens' syndrome segmental wall motion abnormalities are rarely encountered and usually improve after intervention.

\section{Disclosure}

The authors report no conflicts of interest.

\section{References}

1. De Zwann C, Bar FW, Wellens HJJ. Characteristic electrocardiographic pattern indicating a critical stenosis high in left anterior descending coronary artery in patients admitted because of impending myocardial infarction. Am Heart J. 1982;103:730-736.

2. Rhinehardt J, Brady WJ, Perron AD, Mattu A. Electrocardiographic manifestations of Wellens' syndrome. Am J Emerg Med. 2002;20:638-643.

3. Kardesoglu E, Celik T, Cebeci BS, et al. Wellens' syndrome: a case report. J Int Med Res. 2003;31:585-590.

4. De Zwann C, Bar FW, Janssen JH, et al. Angiographic and clinical characteristics of patients with unstable angina showing an ECG pattern indicating critical narrowing of the proximal LAD coronary artery. $\mathrm{Am}$ Heart J. 1989;117:657-665.

5. Tandy TK, Bottomy DP, Lewis JG. Wellens' syndrome. Ann Emerg Med. 1999;33:347-351

6. Nisbet BC, Zlupko G. Repeat Wellens' syndrome: case report of critical proximal left anterior descending artery restenosis. $J$ Emerg Med. 2010;39:305-308
Open Access Emergency Medicine

\section{Publish your work in this journal}

Open Access Emergency Medicine is an international, peer-reviewed, open access journal publishing original research, reports, editorials, reviews and commentaries on all aspects of emergency medicine. The manuscript management system is completely online and includes a very quick and fair peer-review system, which is all easy to use.

\section{Dovepress}

Visit http://www.dovepress.com/testimonials.php to read real quotes from published authors. 